\title{
THOMAS POGGE Could Globalisation Be Good For World Health?
}

\begin{abstract}
Every day thousands of people die from poverty-related causes. Many of these deaths could be avoided if appropriate medical treatments were available to the world's poor. Due to the current structure of the international patent regime, they are not. Since the risks and costs associated with pharmaceutical innovation are extremely high, to incentivise research, inventor firms are granted a temporary monopoly over newly invented drugs. While allowing firms to make up for the costs of research, this has the morally perverse effect of raising the prices of pharmaceuticals to a level where they become unaffordable to the world's poor. To correct this grievous flaw, the paper proposes a concrete and realistic alternative scheme which, by rewarding medical innovators in proportion to the impact of their drugs on the global disease burden, would incentivise the production and selling of crucial drugs for the world's poor at prices accessible to them.
\end{abstract}

KEY WORDS: world poverty, global health, international patents, global justice.

The lives of some 50,000 human beings, mostly children, are cut short every day by avoidable poverty-related causes. These account for one third of all human deaths - 18 million every year. ${ }^{1}$ Hundreds of millions more suffer grievously from such avoidable medical conditions. ${ }^{2}$ The lives of even more are shattered by severe illnesses or premature deaths in their families. These medical problems weigh down the economies of many poor countries, thereby perpetuating their poverty which in turn contributes to the ill health of their populations.

1. In 2002, there were 57 million human deaths. Among the main avoidable causes of death were (with death tolls in thousands): respiratory infections (3963 - mainly pneumonia), HIV/AIDS (2777), perinatal conditions (2462), diarrhea (1798), tuberculosis (1566), malaria (1272), childhood diseases (1124 - mainly measles), maternal conditions (510), malnutrition (485), sexually transmitted diseases (180), meningitis (173), hepatitis (157), and tropical diseases (129). See WHO (World Health Organization) The World Health Report 2004 (Geneva: WHO Publications, 2004), pp. 120-25, also at <www.who.int/whr/2004WHO 2004>

2. Such morbidity is due to the conditions listed in the preceding footnote as well as to a variety of other communicable diseases, including dengue fever, leprosy, trypanosomiasis (sleeping sickness and Chagas disease), onchocerciasis (riverblindness), leishmaniasis, Buruliulcer, lymphatic filariasis, and schistosomiasis (bilharzia). See D. R. Gwatkin and M. Guillot, The Burden of Disease Among the Global Poor: Current Situation, Future Trends, and Implications for Strategy (Washington and Geneva: The World Bank and the Global Forum for Health Research, 1999). 
This huge incidence of mortality and morbidity is not randomly distributed. For a variety of social reasons, females are significantly overrepresented among those suffering severe ill health. ${ }^{3}$ Being especially vulnerable and helpless, children under 5 are also overrepresented, accounting for nearly 60 percent of the death toll. ${ }^{4}$ But the most significant causal determinant is poverty: Nearly all the avoidable mortality and morbidity occurs in the poor countries ${ }^{5}$ and especially among their poorer inhabitants, who lack access to the things that help the rest of us ward off ill health - including adequate nutrition, safe drinking water, improved sanitation, essential medicines, adequate clothing and shelter, and mosquito nets in malaria infested regions. ${ }^{6}$

These huge mortality and morbidity rates can be dramatically reduced by reforming the way we encourage and reward the development of new medical treatments - preventive (like vaccines) or remedial. I will sketch a concrete, feasible, and politically realistic reform plan that would give medical innovators stable and reliable financial incentives to address the medical conditions of the poor. If adopted, this plan would not add much to the overall cost of global health care spending. In fact, on any plausible accounting, which would take note of the huge economic losses caused by the present global disease burden, the reform would actually save money. Moreover, it would distribute the cost of global health care spending more fairly across countries, across generations, and between those lucky enough to enjoy good health and the unlucky ones suffering from serious medical conditions.

The decision about whether and how to implement such a plan obviously rests with national parliaments and international organizations such as the World Trade Organization (WTO) and the World Health Organization (WHO). But these decision makers could benefit from an exploration of the more promising reform options together with a full assessment of their comparative advantages and disadvantages, resulting in a specific reform recommendation.

The existing rules for incentivizing pharmaceutical research are morally deeply problematic. Long recognized among international health experts, this fact has come to be more widely understood in the wake of the AIDS crisis, especially in Africa, where the vital needs of poor patients are pitted against the

3. UNDP (United Nations Development Programme), Human Development Report 2003 (New York: Oxford University Press, 2003), pp.310-30, also at <www.undp.org/hdr2003>; UNIFEM (United Nations Development Fund for Women) 'Eradicating Women's Poverty' (2001), <www.unifem.undp.org/ec_pov. htm>; UNRISD (United Nations Research Institute for Social Development), Gender Equality: Striving for Justice in an Unequal World (Geneva: UNRISD/UN Publications, 2005), also at <www.unrisd.org>

4. UNICEF (United Nations Children's Fund), The State of the World's Children 2005 (New York: UNICEF, 2005), also at <www.unicef.org/sowco5/english>

5. WHO (2004), pp. 120-25.

6. Official statistics report that, among the global poor, 850 million are undernourished, 1037 million lack access to safe water, and 2600 million lack access to improved sanitation, UNDP, Human Development Report 2005, (New York: UNDP, 2005), pp. 24, 44, also at <hdr.undp.org/reports/global/2005>; about 2000 million lack access to essential drugs, <www.fic.nih.gov/about/summary.html>; some 1000 million have no adequate shelter, and 2000 million no electricity, UNDP, Human Development Report 1998 (New York: Oxford University Press, 1998), p. 49. 
need of pharmaceutical companies to recoup their research and development investments. ${ }^{7}$ Still, this wider recognition does not easily translate into political reform. Some believe (like Churchill about democracy) that the present regime is the lesser evil in comparison to its feasible alternatives. Others, more friendly to reform, disagree about what the flaws of the present system are exactly and have put forward a wide range of alternative reform ideas.

What is needed now is a concrete and specific reform plan that is fully informed by the relevant facts and insights from science, statistics, medicine, economics, law, and (moral and political) philosophy. This plan must be fully worked out to the point where it is ready for implementation and can serve as a clear focal point for advocacy, media discussions and for the general public. To have a chance for implementation, the plan must be politically feasible and realistic. To be feasible it must, once implemented, generate its own support from governments, pharmaceutical companies, and the general public (taking these three key constituencies as they would be under the reformed regime). To be realistic, the plan must possess moral and prudential appeal for governments, pharmaceutical companies, and the general public (taking these three constituencies as they are now, under the existing regime). A reform plan that is not incentive-compatible in these two ways is destined to remain a philosopher's pipe dream.

Bringing new, safe and effective life-saving medications to market is hugely expensive, as inventor firms must pay for the research and development of new drugs as well as for elaborate testing and the subsequent approval process. ${ }^{8}$ In addition, newly developed medical treatments often turn out to be unsafe or not effective enough, to have bad side effects, or fail to win government approval for some other reason, which may lead to the loss of the entire investment.

Given such large investment costs and risks, very little innovative pharmaceutical research would take place in a free market system. The reason is that an innovator would bear the full cost of its failures, but would be unable to profit from its successes because competitors would copy or retro-engineer its invention (effectively free-riding on its effort) and then drive down the price close to the marginal cost of production. This is a classic instance of market failure leading to a collectively irrational (Pareto-suboptimal) outcome in which medical innovation is undersupplied by the market.

The classic solution, also prescribed by the TRIPs (Agreement on Trade Related Aspects of Intellectual Property Rights) regime - adopted under WTO auspices in the Uruguay Round - corrects this market failure through patent rules that grant inventor firms temporary monopolies on their inventions, typically for 20 years from the time of filing a patent application. With competitors barred from

7. D. Barnard 'In the High Court of South Africa, Case No. 4138/98: The Global Politics of Access to Low-Cost AIDS Drugs in Poor Countries', Kennedy Institute of Ethics Journal 12/2, (2002), 159-74.

8. This point may be controversial to some extent. It has been asserted that pharmaceutical companies wildly overstate their financial and intellectual contributions to drug development and that most basic research is funded by governments and universities and then made available to the pharmaceutical industry for free. See M. Angell, The Truth about the Drug Companies: How They Deceive Us and What to Do About It (New York: Random House, 2004); Consumer Project on Technology <www.cptech.org/ip/health/econ/rndcosts.html>; UNDP, Human Development Report 2001 (New York: Oxford University Press, 2001), ch. 5, also at <www.undp.org/hdr2001> 
copying and selling any newly invented drug during this period, the inventor firm (or its licensees) can sell it at the profit-maximizing monopoly price typically very far above - as in 400 times greater than - its marginal cost of production. In this way, the inventor firm can recoup its research and overhead expenses plus some of the cost of its other research efforts that failed to bear fruit.

This solution corrects one market failure (undersupply of medical innovation), but its monopoly feature creates another. During the patent's duration, the profitmaximizing sale price of the new medicine will be far above its marginal cost of production. This large differential is socially harmful by causing a 'deadweight loss'. It precludes mutually beneficial sales to potential buyers who are willing and able to pay more than the cost of production, but not the much higher monopoly price. If modified rules could facilitate these potential transactions, then many patients would benefit - and so would the drug companies as they would book additional profitable sales and typically also, through economies of scale, reduce their marginal cost of production. Such a reform would not merely avoid a sizable economic loss for the national and global economies. It would also avoid countless premature deaths and much severe suffering worldwide which the present patent regime engenders by blocking mutually advantageous sales of essential medicines.

There are two basic reform strategies for avoiding this second market failure associated with monopoly pricing powers: differential-pricing and public-good strategies. The differential-pricing strategy comes in different variants. One would have inventor firms themselves offer their proprietary drugs to different customers at different prices, thereby realizing a large profit margin from sales to the more affluent without renouncing sales to poorer buyers at a lower margin. Another variant is the right of governments, recognized under TRIPs rules, to issue compulsory licenses for inventions that are urgently needed in a public emergency. Exercising this right, a government can force down the price of a patented invention by compelling the patent holder to license it to other producers for a set percentage (typically below 10 percent) of the latter's sales revenues. It is often suggested that poor countries should assert their compulsory licensing rights to cope with their public health crises and with the AIDS pandemic in particular.

Differential-pricing solutions are generally unworkable unless the different categories of buyers can be prevented from knowing about, or from trading with, one another. In the real world, if the drug were sold at a lower price to some, then many buyers who would otherwise be willing and able to pay the higher price, would find a way to buy at the lower price. Selling expensive drugs more cheaply in poor countries, for example, would create strong incentives to divert (e.g. smuggle) this drug back into the more affluent countries, leading to relative losses in the latter markets that outweigh the gains in the former. Anticipating such net losses through diversion, inventor firms typically do not themselves try to overcome the second market failure through differential pricing, resist pressures to do so, and fight attempts to impose compulsory licensing upon them. As a result, differential pricing has not gained much of a foothold, and many poor 
patients who would be willing and able to purchase the drug at a price well above the marginal cost of production are excluded from this drug because they cannot afford the much higher monopoly price. ${ }^{9}$ While such exclusion may be acceptable for other categories of intellectual property (software, films, and music), it is morally highly problematic in the case of essential medicines.

To be sure, insofar as a government does succeed, against heavy pressure from pharmaceutical companies and often their governments, in exercising its right to issue compulsory licenses, any net losses due to diversion are simply forced upon the patent holders. But such compulsory licensing, especially if it becomes more common, brings back the first market failure of undersupply. Pharmaceutical companies will tend to spend less on the quest for essential drugs when the uncertainty of success is compounded by the additional unpredictability of whether, and to what extent, they will be allowed to recoup their investments through undisturbed use of their monopoly pricing powers.

In light of these serious problems, I doubt that the differential-pricing strategy can yield a plan for reform that would constitute a substantial improvement over the present regime. So I am proceeding, for now, on the assumption that an exploration of the public-good strategy is more promising, that is, more likely to lead to the formulation of a reform plan that would avoid the main defects of the present monopoly-patent regime while preserving most of its important benefits. The great difficulty to be overcome lies in devising the best possible reform plan within this much larger domain of the public-good strategy.

We may think of such a reform plan as consisting of three components. First, the results of any successful effort to develop (research, test, and obtain regulatory approval for) a new essential drug are to be provided as a public good that all pharmaceutical companies may use free of charge. This reform would eliminate the second market failure (associated with monopoly pricing powers) by allowing competition to bring the prices of new essential drugs down close to their marginal cost of production. Implemented in only one or a few countries, this reform would engender problems like those we have found associated with differential-pricing solutions. Cheaper drugs produced in countries where drug development is treated as a public good, would seep back into countries adhering to the monopoly-patent regime, undermining research incentives in the latter. The reform should therefore be global in scope, just like the rules of the current TRIPs regime are. The first reform component then, is that results of successful efforts to develop new essential drugs are to be provided as public goods that all pharmaceutical companies anywhere may use free of charge.

Implemented in isolation, this first reform component would destroy incentives for pharmaceutical research. This effect is avoided by the second component which is that, similar to the current regime, inventor firms should be entitled to take out a multi-year patent on any essential medicines they invent, but, during the life of the patent, should be rewarded, out of public funds, in proportion to the

9. P. Kanavos, J. Costa-i-Font, S. Merkur, and M. Gemmill, 'The Economic Impact of Pharmaceutical Parallel Trade in European Union Member States', (2004), LSEWorking Paper, <www.lse.ac.uk/collections/LSEHealthAndSocialCare/pdf/ Workingpapers/Paper.pdf> 
impact of their invention on the global disease burden. This reform component would reorient the incentives of such firms in highly desirable ways. Any inventor firm would have incentives to sell its innovative treatments cheaply (often even below their marginal cost of production) in order to help get its drugs to even very poor people who need them. Such a firm would have incentives to prioritize prevention over treatment (the conventional patent system has the opposite effect, with new treatments offering much greater profit opportunities than new vaccines). It would have incentives also to ensure that patients are fully instructed in the proper use of its drugs (dosage, compliance, etc.), so that, through wide and effective deployment, they have as great an impact on the global disease burden as possible. ${ }^{10}$ Rather than ignore poor countries as unlucrative markets, inventor firms would have incentives to work together toward improving the health systems of these countries in order to enhance the impact of their inventions there. In addition, any inventor firm would have reason to encourage and support efforts by cheap generic producers (well-established in India, Brazil and South Africa, for example) to copy its drugs, because such copying would further increase the number of users and hence the invention's favorable impact on the global disease burden. In all these ways, the reform would align and harmonize the interests of inventor firms with those of patients and the generic drug producers - interests that, under the current regime, are diametrically opposed. ${ }^{11}$ The reform would also align the moral and prudential interests of the inventor firms who, under the present regime, are forced to choose between recouping their investments in the search for essential drugs or preventing avoidable suffering and deaths.

This second component of a plausible public-good strategy realizes yet another tremendous advantage over the status quo. Under the current regime, inventor firms have incentives to try to develop a new medical treatment only if the expected value of the temporary monopoly pricing power they might gain, discounted by the probability of failure, is greater than the full development and patenting costs. They have no incentives, then, to try to develop any treatment that few people have a need for or that is needed by people unable to afford it at a price far above the marginal cost of production. The former category contains treatments for many so-called orphan diseases which affect only small numbers of patients. The latter category contains many diseases mainly affecting the poor, for which treatments priced far above the marginal cost of production could be sold only in small quantities. It may be acceptable that no one is developing software demanded only by a few and that no one is producing music valued only by the very poor. But it is morally problematic that few treatments are developed for rare diseases, and it is extremely problematic, morally, that so few treatments are developed for medical conditions that cause most of the premature deaths and

10. The absence of such incentives under the present rules gravely undermines the effectiveness even of donated drugs delivered into poor regions, UNDP (2001), p. 101.

11. This opposition was displayed most dramatically when a coalition of 31 pharmaceutical companies went to court in South Africa in order to prevent their inventions from being reproduced by local generic producers and sold cheaply to desperate patients whose life depended on such affordable access to these retroviral drugs. In April 2001, the attempted law suit collapsed under a barrage of worldwide public criticism, Barnard (2002). 
suffering in the world today. Even if common talk of the 10/90 gap ${ }^{12}$ is now an overstatement, the problem is certainly real: malaria, pneumonia, diarrhea, and tuberculosis, which together account for 21 percent of the global disease burden, receive 0.31 percent of all public and private funds devoted to health research ${ }^{13}$. And diseases confined to the tropics tend to be the most neglected. Of the 1393 new drugs approved between 1975 and 1999, only 13 were specifically indicated for tropical diseases and, of these 13, five were byproducts of veterinary research and two had been commissioned by the military. ${ }^{14}$

Rewarding pharmaceutical research in proportion to its impact on the global disease burden would attract inventor firms toward medical conditions whose adverse effects on humankind can be reduced most cost-effectively. This reorientation would greatly mitigate the problem of neglected diseases that overwhelmingly affect the poor. And it would provide new profitable research opportunities for pharmaceutical companies.

One may worry that the second component of the reform would also reduce incentives to develop treatments for medical conditions that, though they add little to the global disease burden (on any plausible conception thereof), affluent patients are willing to pay a lot to avoid. This worry can be addressed, at least in part, by limiting the application of the reform plan to essential drugs, that is, to medicines for diseases that destroy human lives. Drugs for other medical conditions, such as hair loss, acne, and impotence, for example, can remain under the existing regime with no loss in incentives or rewards.

Incorporating this distinction between essential and non-essential drugs into the reform plan raises the specter of political battles over how this distinction is to be defined and of legal battles over how some particular invention should be classified. These dangers could be averted by allowing inventor firms to classify their inventions as they wish, and then designing the rewards in such a way that these firms will themselves choose to register under the reform rules any inventions that stand to make a substantial difference to the global disease burden. Such freedom of choice would also greatly facilitate a smooth and rapid phasing-in of the new rules, as there would be no disappointment of the legitimate expectations of firms that have undertaken research for the sake of gaining a conventional patent. The reform plan should be attractive for pharmaceutical companies by winning them new lucrative opportunities for research into currently neglected diseases without significant losses in the lucrative research opportunities they now enjoy - and by restoring their moral stature as benefactors of humankind.

This second reform component requires a way of funding the planned incentives

12. 'Only 10 percent of global health research is devoted to conditions that account for 90 percent of the global disease burden', DNDWG (Drugs for Neglected Diseases Working Group) Fatal Imbalance: The Crisis in Research and Development for Drugs for Neglected Diseases (Geneva: MSF and DNDWG, 2001), p. 10, also at <www.msf.org/source/access/2001/fatal/fatal.pdf>; cf. GFHR (Global Forum for Health Research), The 10/90 Report on Health Research 2003-2004 (Geneva: GFHR, 2004), also at <www.globalforumhealth. org $>$. This imbalance may have been reduced, notably through spending by the Gates Foundation.

13. GFHR (2004), p. 122.

14. Trouiller et al., 'Drugs for Neglected Diseases: A Failure of the Market and a Public Health Failure?',

Tropical Medicine and International Health 6/11 (2001), 945-51, p.11 
for developing new essential medicines, which might cost some $\$ 45-90$ billion annually on a global scale. (A more precise estimate is impossible because the cost each year would depend on how successful innovative treatments would be in reducing the global disease burden. ${ }^{15}$ The reform would cost billions of dollars only if and insofar as it would save millions of lives). The third component of the reform plan is then to develop a fair, feasible and politically realistic allocation of these costs, as well as compelling arguments in support of this allocation.

While the general approach as outlined may seem plausible enough, the great intellectual challenge is to specify it concretely in a way that shows it to be both feasible and politically realistic. Here one main task, associated with the second component, concerns the design of the planned incentives. This requires a suitable measure of the global disease burden and ways of assessing the contributions that various new medical treatments are making to its reduction. When several medicines are alternative treatments for the same disease, then the reward corresponding to their aggregate impact must be allocated among their respective inventors on the basis of each medicine's market share and effectiveness. More complex is the case (exemplified in the fight against HIV, tuberculosis and malaria) of 'drug cocktails' that combine several drugs developed by different companies. Here the reform plan must formulate clear and transparent rules for distributing the overall reward, proportional to the impact of the drug cocktail, among the inventors of the drugs it contains. And it must also include specific rules for the phase-in period so as not to discourage ongoing research efforts motivated by the existing patent rules. It is of crucial importance that all these rules be clear and transparent, lest they add to the inevitable risks and uncertainties that complicate the work of inventor firms and sometimes discourage them from important research efforts. This task requires expertise in medicine, statistics, economics, and legal regulation.

Another main task, associated with the third component, concerns the design of rules for allocating the cost of the incentives as well as the formulation of good arguments in favor of this allocation. Effective implementation of the reform requires that much of its cost be borne by the high-income countries which, with 15.8 percent of the world's population, control 80.5 percent of the global social product. This is feasible even if these countries, after re-targeting existing subsidies to the pharmaceutical industry in accordance with the reformed rules, still had to shoulder around $\$ 70$ billion in new expenditures. This amount, after all, is only 0.22 percent of the aggregate gross national incomes of the high-income countries or $\$ 70$ for each of their residents. ${ }^{16}$ To make this planned spending increase realistic,

15. My rough estimate assumes that the reformed rules would stimulate the pharmaceutical industry to spend somewhat more on research toward developing new essential drugs (especially for heretofore neglected diseases) than it is now spending on all pharmaceutical research: $c f$. GFHR (2004), p. 112. I also assume that the rewards offered under the reformed rules must not merely match, but substantially exceed these projected expenditures, because pharmaceutical companies will brave the risks and uncertainties of an expensive and protracted research effort only if its expected return substantially exceeds its cost.

16. For the aggregate gross national income ( $\$ 32,064$ and $\$ 39,834$ billion) and the aggregate population (1001 and 6345 million) of the high-income countries and the whole world in 2004, see; World Bank, World Development Report 2006 (New York: Oxford University Press, 2005), p. 293. 
the taxpayers and politicians of the high-income countries need to be given compelling reasons for supporting it.

This expense can be supported by prudential considerations. The taxpayers of the wealthier countries gain a substantial benefit for themselves in the form of lower drug prices and/or insurance premiums. To be sure, such a shifting of costs, within affluent countries, from patients to taxpayers would benefit lesshealthy citizens at the expense of healthier ones. But such a mild mitigation of the effects of luck is actually morally appealing - not least because even those fortunate persons who never, or rarely, need to take advantage of recent medical advances still benefit from pharmaceutical research which affords them the peace of mind derived from knowing that, should they ever become seriously ill, they would have access to superb medical knowledge and treatments.

A second prudential reason is that, by making pharmaceutical research sensitive to the interests also of poor populations, we are building good will in the developing world by demonstrating in a tangible way our concern for their horrendous public-health problems. This argument has a moral twin: in light of the extent of avoidable mortality and morbidity in the developing world, the case for including the interests of the poor is morally compelling.

These last twin arguments have wider application. The reform plan would not merely encourage the same sort of pharmaceutical research differently, but would also expand the range of medical conditions for which inventor firms would seek solutions. Under the current regime, these firms understandably show little interest in tropical diseases, for example, because, even if they could develop successful treatments, they would not be able to make much money from selling or licensing them. Under the alternative regime I suggest we design, inventor firms could make lots of money by developing such treatments whose potential impact on the global disease burden is enormous. Measles, malaria, and tuberculosis, each kill well over a million people per year, mostly children, and pneumonia kills more than the other three combined. New drugs could dramatically reduce the impact of these diseases.

There are three further prudential reasons. The reform would create topflight medical-research jobs in the developed countries. It would enable us to respond more effectively to public health emergencies and problems in the future by earning us more rapidly increasing medical knowledge combined with a stronger and more diversified arsenal of medical interventions. In addition, better human health around the world would reduce the threat we face from invasive diseases. The SARS outbreak and the avian flu scare illustrate the last two points. Dangerous diseases can rapidly transit from poor-country settings into cities in the industrialized world; and the current neglect of the medical needs of poor populations leaves us unprepared to deal with such problems when we are suddenly confronted with them. Bringing enormous reductions in avoidable suffering and deaths worldwide, the reform would furthermore be vastly more cost-effective, and also be vastly better received in the poor countries than similarly expensive humanitarian interventions we have undertaken in recent years and the huge, unrepayable loans our governments and their international 
financial institutions tend to extend to (often corrupt and oppressive) rulers and elites in the developing countries. Last, not least, there is the important moral and social benefit of working with others, nationally and internationally, toward overcoming the morally preeminent problem of our age, which is the horrendous, poverty-induced and largely avoidable morbidity and mortality in the developing world.

Thomas Pogge

Centre for Applied Philosophy and Public

Ethics, Australian National University,

and Department of Political Science,

Columbia University

Thomas.Pogge@anu.edu.au

\section{the globaljusticenetwork}

